\title{
A study on the influence of the dissolution test factors on in vitro release of ibuprofen from sustained release tablets
}

\author{
Alexandra PALI ${ }^{1}$, Georgiana Cristina ORDEAN¹, Greta Maria POMIAN¹, Luca Liviu RUS², \\ Rares Iuliu IOVANOV ${ }^{1}$ \\ ${ }^{1}$ Department of Pharmaceutical Technology and Biopharmacy, Faculty of Pharmacy, \\ "Iuliu Hatieganu" University of Medicine and Pharmacy, Cluj-Napoca, Romania \\ ${ }^{2}$ Preclinical Department, Faculty of Medicine, "Lucian Blaga" University, Sibiu, Romania
}

\begin{abstract}
Objectives. The aim of this study was to investigate the influence of in vitro release test parameters on the release of ibuprofen from sustained release inert matrix tablets.

Materials and methods. Ibuprofen sustained release inert matrix tablets were manufactured at a laboratory scale using Kollidon ${ }^{\circledR} S R$ as matrix formator. The variables of in vitro release study were: dissolution media $\mathrm{pH}$ (7.2-6.8-5.4-1.2), apparatus type (rotative basket and rotative paddle) and stirring speed (50 rpm and $100 \mathrm{rpm}$ ).

Outcomes. An increase in ibuprofen solubility together with an increase on $\mathrm{pH}$ value was observed. Percentage drug release increases together with the increase of $\mathrm{pH}$. Rotative paddle apparatus proved to generate much powerful hydrodynamic forces in comparison with rotative basket apparatus which leads to a rapid in vitro release. Increasing stirring speed will determine a faster release of ibuprofen from matrix tablets. Statistical comparison of release profiles was performed by means of similarity factor f2. Both statistical release profiles comparison (between apparatuses and between stirring speeds) showed no influences of apparatus type and stirring speed on in vitro release at $p H 1.2$ and 5.4. At $p H$ 6.8 and 7.2 there are strong influences of both apparatus type and stirring speed on ibuprofen release from matrix tablets. Modeling of release kinetics showed a good fitting by Weitbull and Korshmeyer-Peppas equations (especially at pH 6.8 and 7.2) and a fair fitting by Higuchi equation (at pH 1.2 and 5.4).

Conclusions. In vitro release of ibuprofen from sustained release matrix tablets depends on dissolution media $\mathrm{pH}$ and release rate depends on judicious choice of dissolution test factors to made precise in vitro/in vivo correlations.
\end{abstract}

Keywords: in vitro release, dissolution test factors, drug-release models

\section{INTRODUCTION}

Release rate of APIs from solid pharmaceutical dosage forms and also absorption rate is determined by dissolution so in vitro release plays an important role in predicting biopharmaceutical profile of a drug [1].

According to the Biopharmaceutical Classification System (BCS), ibuprofen is included in class II (due to its high permeability and low solubility). Bioavailability of pharmaceutical dosage forms containing APIs included in BCS II is limited by dissolution rate [2].

Modified-release dosage forms are used in therapy for more than 50 years and are an important field for pharmaceutical companies (R\&D) and also for academics. An ideal MR dosage form can improve therapy and can offer the patient the following benefits: reduced administration frequency, adequate plasmatic concentrations, enhanced bioavailability and compliance [3]. Formulation of ibuprofen and the strategies applied to modulate its delivery, to acquire specific therapeutic 
benefits, are still under research $[4,5]$.

Oral bioavailability of a drug is dictated by physicochemical properties but also by physiological conditions [6].

In the manufacturing of sustained release matrix tablets, Kollidon ${ }^{\circledR}$ SR is often used due to its excellent pharmaceutical properties (flowability, compressibility etc.) [7].

There are a few studies describing the determination of critical parameters of drug substances that may influence the dissolution but also the comparison of different apparatuses and conditions (media, surfactants, stirring speed) $[8,9]$.

\section{AIM}

The aim of this paper was to investigate the influence of in vitro release test parameters on the release of ibuprofen from sustained release inert matrix tablets.

\section{MATERIALS AND METHODS}

\section{Materials}

Ibuprofen was supplied by Hubei Biocause Pharmaceutical Company Ltd., China. As diluent, directly compressible lactose (lactose DC) (Supertab 14 SD) from DMVFonterra Excipients GmbH\&Co, Germany, was used. Kollidon ${ }^{\circ} \mathrm{SR}$, from BASF-Germany, was chosen as matrix-forming excipient. To ensure free flow of powder blends and also as anticaking agent, hydrophilic fumed silica (Aerosil' 200), from Degussa AG - Germany, was used. Lubricant (magnesium stearate) was produced by UNDESA, Spain.

\section{Reagents}

Monopotassium phosphate, sodium acetate and potassium chloride were supplied by Chemical Company, Romania. Sodium hydroxide, glacial acetic acid and concentrated hydrochloric acid were manufactured by Merck - Germany, Sigma Aldrich Germany and Nordic Invest Romania, respectively. All reagents were analytical grade. In all experiments distilled water was used.

\section{Tablets preparation}

All powders were weighed on a three decimal places balance (Sartorius, Germany), passed through an $800 \mu \mathrm{m}$ sieve and mixed in Mixer Y5, Y-shaped mixing vessel (Erweka, Germany). Due to excellent properties of powder blends (flowability and compressibility - data not shown) tablets were prepared by means of direct compression method using an eccentric tablet press Korsch EK-0 (Korsch, Germany) equipped with a $9 \mathrm{~mm}$ die, with flat punch. Also crushing strength, friability and disintegration time were within the European Pharmacopoeia requirements (data not shown). Qualitative and quantitative composition of tablets is presented in Table 1.

TABLE 1. Qualitative and quantitative composition of the tablets

\begin{tabular}{|l|c|c|c|c|}
\hline \multicolumn{1}{|c|}{ Raw material - type } & Supplier & $\begin{array}{c}\text { Composition } \\
\text { (mg/tablet) }\end{array}$ & $\begin{array}{c}\text { Percen- } \\
\text { tage }\end{array}$ & $\begin{array}{c}\text { Laboratory } \\
\text { batch } \\
\text { (for } \mathbf{7 5} \mathbf{~ g} \text { ) }\end{array}$ \\
\hline Ibuprofen - API & Hubei Biocause & 400.00 & 53.33 & 40.00 \\
\hline Supertab 14 SD - filler & DMV-Fonterra & 203.75 & 27.17 & 20.38 \\
\hline Kollidon $^{\circledR}$ SR - matrix-formator & BASF & 135.00 & 18.00 & 13.50 \\
\hline Aerosil 200 - anticaking agent & Degussa AG & 3.75 & 0.50 & 0.38 \\
\hline Magnesium stearate - lubricant & UNDESA & 7.50 & 1.00 & 0.75 \\
\hline \multicolumn{2}{|r|}{ Total core } & 750.00 & 100.00 & 75.00 \\
\hline \multicolumn{2}{|r}{} & & & \\
\hline
\end{tabular}


Ibuprofen solubility determination

The solubility of ibuprofen in different dissolution media was determined: phosphate buffers $\mathrm{pH}$ $7.2(40 \mathrm{mM})$, phosphate buffers $\mathrm{pH}$ $6.8(40 \mathrm{mM})$, acetate buffers $\mathrm{pH} 5.4$ (40 mM), hydrochloric acid potassium chloride $(0.1 \mathrm{M})$. $\mathrm{pH}$ measurement was performed on an MP 225 pH-meter (Mettler Toledo, USA). Solubilities were determined in dissolution vessels at $37^{\circ} \mathrm{C}$ under stirring. Samples were extracted after 24 hours, filtered and after appropriate dilutions with dissolution media the absorbance was measured at $221 \mathrm{~nm}$ by means of Specord 200 Plus spectrophotometer (Analytik Jena, Germany). In all cases corresponding buffer was used as blank.

In vitro release of ibuprofen from sustained release tablets In vitro release was tested by means of an PT-DT7 dissolution tester (PharmaTest, Germany) equipped with rotative basket (No. 1) and on PT-WS 100 dissolution tester (PharmaTest, Germany) equipped with rotative paddle (No. 2). Dissolution media (900 ml) were the buffers solution described in the section Ibuprofen solubility determination. In all cases USP/EP Borosilicate glass vessel were used. Stirring speeds of 50 and $100 \mathrm{rpm}$ were studied. Experimental design of this study is presented in Table 2 .

Each time, $4 \mathrm{ml}$ of dissolution samples were extracted and replaced with fresh dissolution media in order to keep constant the dissolution media volume $(900 \mathrm{ml})$. Sampling times were: 0.5-1-1.5-22.5-3-4-5-6-8-10-12-24 hours. After filtering, appropriate dilutions of samples were performed (with $\mathrm{mLine}$ semi-automatic pipettes from Sartorius). The absorbance was measured at $221 \mathrm{~nm}$ by means of Specord 200 Plus spectrophotometer (Analytik Jena, Germany). In all cases corresponding buffer was used as blank.

\section{Release kinetics and statistical} comparison of in vitro release profiles

Modeling and comparison of dissolution profiles was performed by means of DDSolver (a freeware software working on Microsoft Excel platform) [10].

TABLE 2. Experimental design of in vitro release study

\begin{tabular}{|c|c|c|c|}
\hline $\mathbf{p H}$ & $\begin{array}{c}\text { Apparatus } \\
\text { type }\end{array}$ & $\begin{array}{c}\text { Stirring } \\
\text { speed (rpm) }\end{array}$ & Symbol \\
\hline 7.2 & 1 & 50 & $7.250 \mathrm{~B}$ \\
\hline 6.8 & 1 & 50 & $6.850 \mathrm{~B}$ \\
\hline 5.4 & 1 & 50 & $5.450 \mathrm{~B}$ \\
\hline 1.2 & 1 & 50 & $1.250 \mathrm{~B}$ \\
\hline 7.2 & 2 & 50 & $7.250 \mathrm{P}$ \\
\hline 6.8 & 2 & 50 & $6.850 \mathrm{P}$ \\
\hline 5.4 & 2 & 50 & $5.450 \mathrm{P}$ \\
\hline 1.2 & 2 & 50 & $1.250 \mathrm{P}$ \\
\hline 7.2 & 1 & 100 & $7.2100 \mathrm{~B}$ \\
\hline 6.8 & 1 & 100 & $6.8100 \mathrm{~B}$ \\
\hline 5.4 & 1 & 100 & $5.4100 \mathrm{~B}$ \\
\hline 1.2 & 1 & 100 & $1.2100 \mathrm{~B}$ \\
\hline 7.2 & 2 & 100 & $7.2100 \mathrm{P}$ \\
\hline 6.8 & 2 & 100 & $6.8100 \mathrm{P}$ \\
\hline 5.4 & 2 & 100 & $5.4100 \mathrm{P}$ \\
\hline 1.2 & 2 & 100 & $1.2100 \mathrm{P}$ \\
\hline & & & \\
\hline
\end{tabular}


Similarity factor $\mathrm{f}_{2}$ was used to statistically compare in vitro release profiles. This factor (indicating the closeness between two release profiles) is defined by the following equation (1).

$f_{1}=s 0 \times \log \left\{\left[1+\frac{1}{n} \sum_{i=1}^{n}\left(R_{t}-T_{x}\right)^{2}\right]^{-0.5} \times 100\right\}$

Where: $R_{t}$ and $T_{t}$ are the percentage of reference and test profile, at time $t$ and $n$ is the number of sampling points.

According to European Medicines Agency, values of $f_{2}$ between 50 and 100 indicate the sameness of two in vitro release profiles. Evaluation of the goodness of fit of a model includes the calculation of coefficient of determination $\left(R^{2}\right)$ and of adjusted coefficient of determination $\left(R_{\text {adj }}^{2}\right)[11,12]$.

\section{RESULTS AND DISCUSSION}

Solubility determination of ibuprofen showed an increase in solubility (fig. 1) together with an increase in $\mathrm{pH}$ value $\mathrm{pH}=1.2-\mathrm{S}=$ $0.05 \mathrm{mg} / \mathrm{ml} ; \mathrm{pH}=5.4-\mathrm{S}=0.52$ $\mathrm{mg} / \mathrm{ml} ; \mathrm{pH}=6.8-\mathrm{S}=2.18 \mathrm{mg} / \mathrm{ml}$; $\mathrm{pH}=7.4-\mathrm{S}=3.89 \mathrm{mg} / \mathrm{ml}$ ).

In vitro release profiles of ibuprofen in different dissolution condition are presented in Figure 2 .

Influence of the dissolution media $\mathrm{pH}$ on in vitro release of ibuprofen In both cases (rotative basket

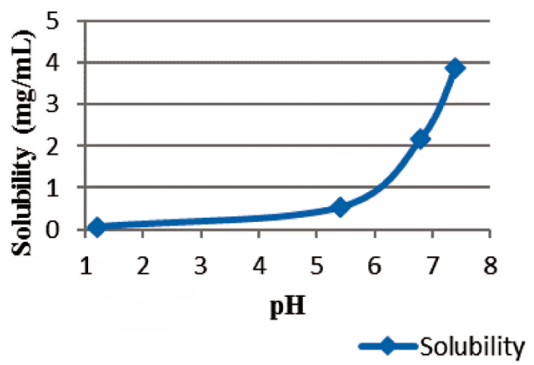

FIGURE 1. Ibuprofen solubility variation versus $\mathrm{pH}$ apparatus and rotative paddle apparatus) percentage drug release increases together with the increase of $\mathrm{pH}$ due to higher ibuprofen solubility in phosphate buffers in comparison with its solubility in acetate and hydrochloric buffers (fig. 2).

Influence of dissolution apparatus type on in vitro release of ibuprofen Dissolution apparatus type has a significative influence on in vitro release of ibuprofen. Hydrodynamic forces are much powerful in case of rotative paddle apparatus in comparison with rotative basket apparatus and consequently in vitro release is more rapid (fig. 3). Also, some excipients may remain on the sieve of the basket, somehow explaining why release on rotative basket apparatus is lower.

Similarity factors for release profiles (tested at the same $\mathrm{pH}$ and the same stirring speed but on different apparatus type) were calculated (Table 3).

TABLE 3. Statistical release profiles comparison (between apparatuses)

\begin{tabular}{|c|c|}
\hline $\begin{array}{c}\text { Release profiles } \\
\text { comparison }\end{array}$ & $\begin{array}{c}\text { Similarity } \\
\text { factor } \mathrm{f}_{2}\end{array}$ \\
\hline $7.250 \mathrm{~B}$ and 7.2 50 P & 41.59 \\
\hline $7.2100 \mathrm{~B}$ and 7.2 100 P & 38.84 \\
\hline $6.850 \mathrm{~B}$ and 6.8 50 P & 34.34 \\
\hline $6.8100 \mathrm{~B}$ and 6.8 100 P & 17.92 \\
\hline 5.4 50 B and 5.4 50 P & 85.19 \\
\hline 5.4 100 B and 5.4 100 P & 94.48 \\
\hline $1.250 \mathrm{~B}$ and 1.2 50 P & 96.79 \\
\hline $1.2100 \mathrm{~B}$ and 1.2 100 P & 84,79 \\
\hline
\end{tabular}

As stated in table 3 , apparatus type does not influence release profiles at $\mathrm{pH} 1.2$ and $5.4\left(50<\mathrm{f}_{2}<100\right)$. Release profiles corresponding to $\mathrm{pH} 6.8$ and $\mathrm{pH} 7.2$ are under a strong influence of apparatus type $\left(\mathrm{f}_{2}<50\right)$.

Influence of stirring speed on in vitro release of ibuprofen As presented in figure 4, a bigger stirring speed will determine a 

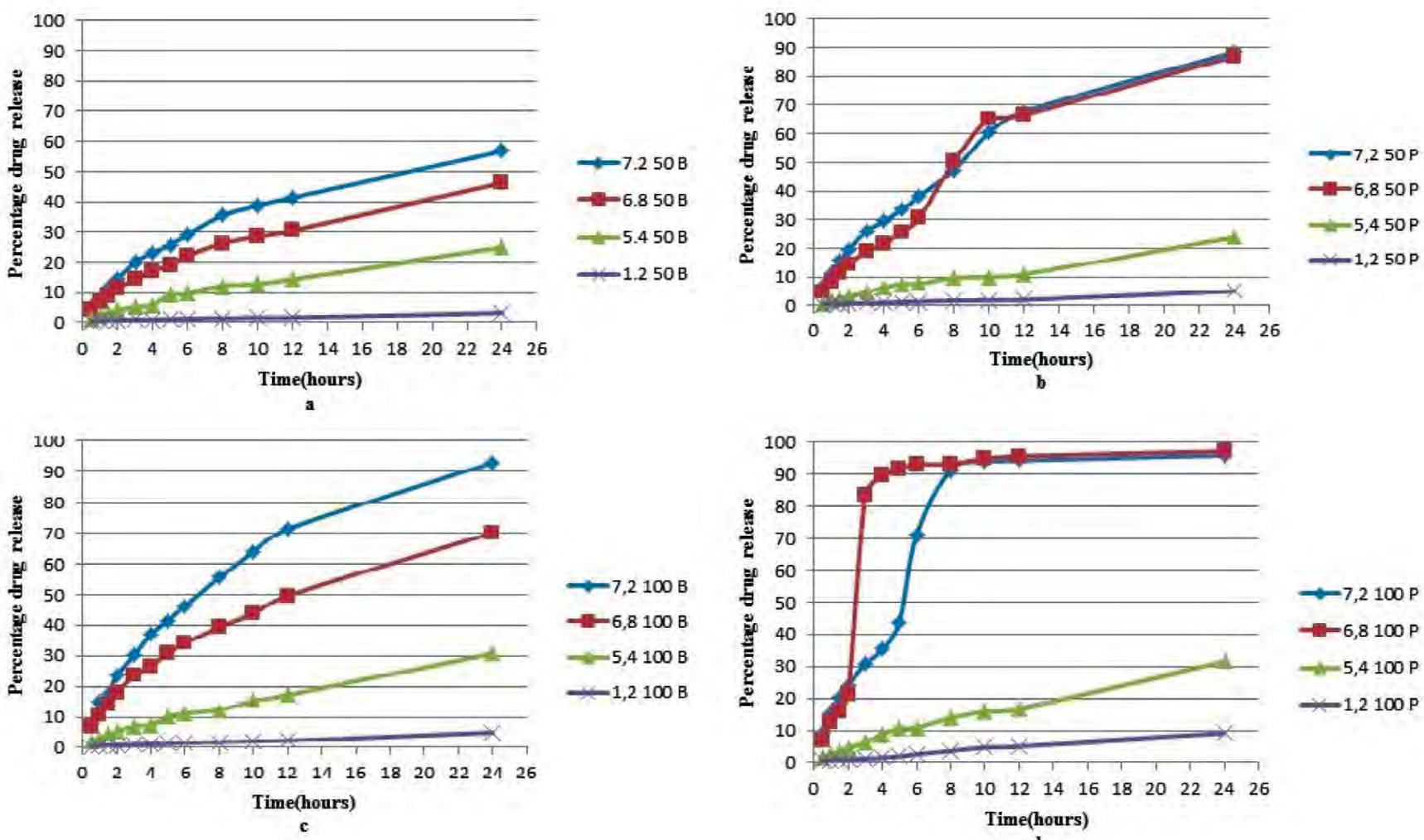

FIGURE 2. Drug release profiles for rotative basket apparatus (50 rpm - a; $100 \mathrm{rpm}-c)$ and for rotative paddle apparatus (50 rpm - b; $100 \mathrm{rpm}-d$ )

faster in vitro release of ibuprofen from sustained release tablets. Again, hydrodynamics plays an important role on dissolution.

Similarity factors for release profiles (tested at the same $\mathrm{pH}$ and on the same apparatus type but using different stirring speed) were calculated (Table 4).

TABLE 4. Statistical release profiles comparison (between stirring speeds)

\begin{tabular}{|c|c|}
\hline $\begin{array}{c}\text { Release profiles } \\
\text { compared }\end{array}$ & $\begin{array}{c}\text { Similarity } \\
\text { factor } \mathrm{f}_{2}\end{array}$ \\
\hline 7.2 50 B and 7.2 100 B & 36.26 \\
\hline $7.250 \mathrm{P}$ and 7.2 50 P & 34,25 \\
\hline $6.850 \mathrm{~B}$ and 6.8 100 B & 45.03 \\
\hline $6.850 \mathrm{P}$ and 6.8 100 P & 19.08 \\
\hline 5.4 50 B and 5.4 100 B & 80.19 \\
\hline 5.4 50 P and 5.4 100 P & 69.76 \\
\hline $1.250 \mathrm{~B}$ and 1.2 100 B & 96.38 \\
\hline $1.250 \mathrm{P}$ and 1.2 100 P & 84.05 \\
\hline
\end{tabular}

As stated in table 4, stirring speed does not influence release profiles at $\mathrm{pH} 1.2$ and $5.4\left(50<\mathrm{f}_{2}<100\right)$.

Release profiles corresponding to $\mathrm{pH}$
6.8 and $\mathrm{pH} 7.2$ are under a strong influence of stirring speed $\left(f_{2}<50\right)$.

In vitro release profiles modeling

All dissolution profiles were fitted

TABLE 5. Goodness of fit for kinetic release models for ibuprofen

\begin{tabular}{|c|c|c|c|c|c|c|c|}
\hline Kinetic model & Wei & bull & & nover_P & pas & & chi \\
\hline Profile symbol & $\mathbf{R}^{2}$ & $\mathbf{R}^{2}{ }_{\text {adj }}$ & $\mathbf{n}$ & $\mathbf{R}^{2}$ & $\mathbf{R}_{\text {adj }}^{2}$ & $\mathbf{R}^{2}$ & $\mathbf{R}_{\text {adj }}{ }^{2}$ \\
\hline $7.250 \mathrm{~B}$ & 0.9979 & 0.9975 & 0.55 & 0.9542 & 0.9496 & 0.9833 & 0.9833 \\
\hline $6.850 \mathrm{~B}$ & 0.9954 & 0.9943 & 0.61 & 0.9894 & 0.9883 & 0.9844 & 0.9844 \\
\hline $5.450 \mathrm{~B}$ & 0.9882 & 0.9856 & 0.78 & 0.9825 & 0.9807 & 0.9090 & 0.9090 \\
\hline $1.250 \mathrm{~B}$ & 0.9083 & 0.8879 & 0.52 & 0.9344 & 0.9279 & 0.9303 & 0.9303 \\
\hline $7.250 \mathrm{P}$ & 0.9762 & 0.9710 & 0.56 & 0.9755 & 0.9730 & 0.9534 & 0.9534 \\
\hline $6.850 \mathrm{P}$ & 0.9507 & 0.9397 & 0.80 & 0.9235 & 0.9158 & 0.8716 & 0.8716 \\
\hline $5.450 \mathrm{P}$ & 0.9649 & 0.9571 & 0.81 & 0.9761 & 0.9737 & 0.8554 & 0.8554 \\
\hline $1.250 \mathrm{P}$ & 0.8799 & 0.8532 & 0.51 & 0.8720 & 0.8592 & 0.8094 & 0.8094 \\
\hline $7.2100 \mathrm{~B}$ & 0.9889 & 0.9864 & 0.56 & 0.9607 & 0.9568 & 0.9791 & 0.9791 \\
\hline $6.8100 \mathrm{~B}$ & 0.9925 & 0.9908 & 0.56 & 0.9940 & 0.9934 & 0.9898 & 0.9898 \\
\hline $5.4100 \mathrm{~B}$ & 0.9752 & 0.9697 & 0.68 & 0.9886 & 0.9875 & 0.9058 & 0.9058 \\
\hline $1.2100 \mathrm{~B}$ & 0.8859 & 0.8605 & 0.60 & 0.9213 & 0.9135 & 0.8695 & 0.8695 \\
\hline $7.2100 \mathrm{P}$ & 0.9208 & 0.9032 & 0.69 & 0.7334 & 0.7067 & 0.8250 & 0.8250 \\
\hline $6.8100 \mathrm{P}$ & 0.9246 & 0.9079 & 0.39 & 0.2592 & 0.1851 & 0.5966 & 0.5966 \\
\hline $5.4100 \mathrm{P}$ & 0.9815 & 0.9773 & 0.76 & 0.9928 & 0.9921 & 0.8993 & 0.8993 \\
\hline $1.2100 \mathrm{P}$ & 0.9843 & 0.9809 & 0.81 & 0.9708 & 0.9679 & 0.8171 & 0.8171 \\
\hline
\end{tabular}

by means of Weitbull, KorsmeyerPeppas and Higuchi models

(Table 5). 

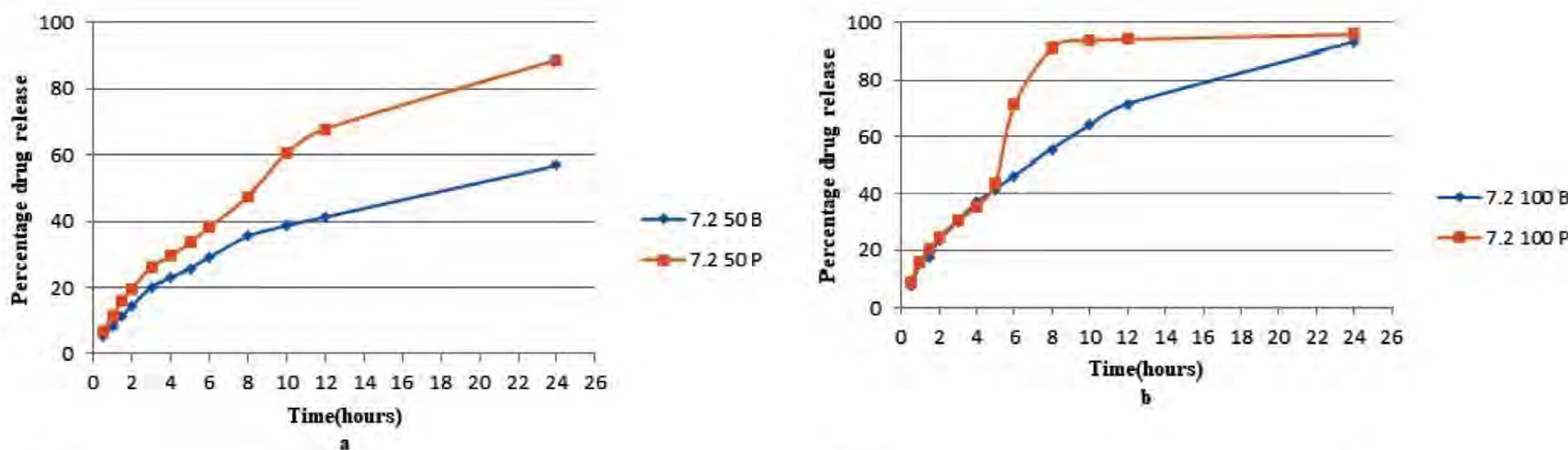

$-7.2100 \mathrm{P}$
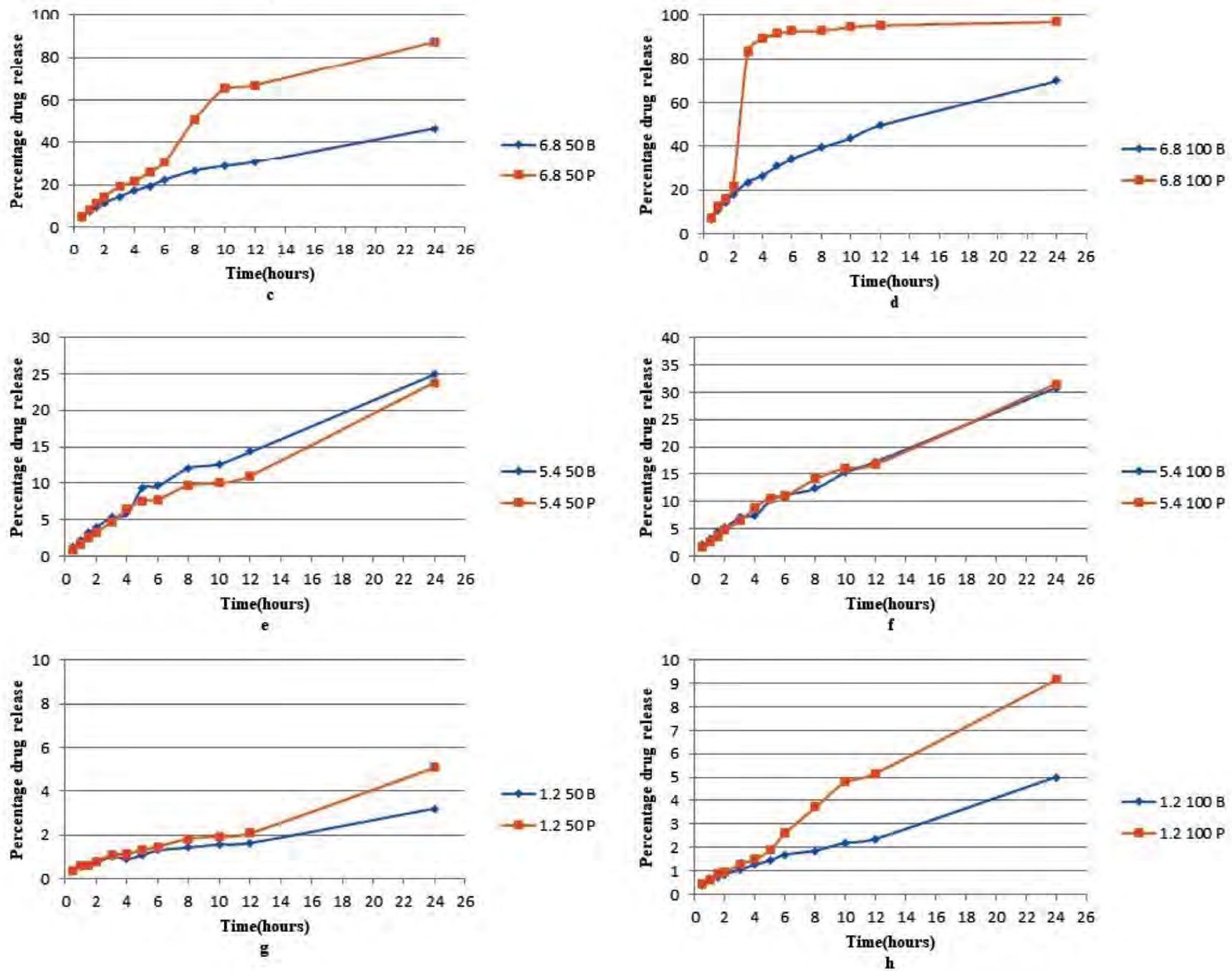

FIGURE 3. Influence of dissolution apparatus type on in vitro release of ibuprofen (pH 7.2-a and b; $p H 6.8 \mathrm{c}$ and d; $\mathrm{pH} 5.4 \mathrm{e}$ and f; $p H 1.2 g$ and $h$ )

Good fitting was achieved by using Weitbull and Korsmeyer-Peppas models (especially at $\mathrm{pH} 6.8$ and 7.2). Trying to explain release data with Higuchi equation resulted in a fair goodness of fit but somehow poorer (especially at low $\mathrm{pH}$ and high stirring speed) than the one obtained by means of Weitbull and Korsmeyer-Peppas models.

\section{CONCLUSIONS}

Sustained release matrix tablets with ibuprofen were manufactured. Factors related to experimental design of in vitro release testing were dissolution media $\mathrm{pH}$, apparatus type and stirring speed.

Solubility of ibuprofen and percentage drug release proved to increase together with the increase of $\mathrm{pH}$. 

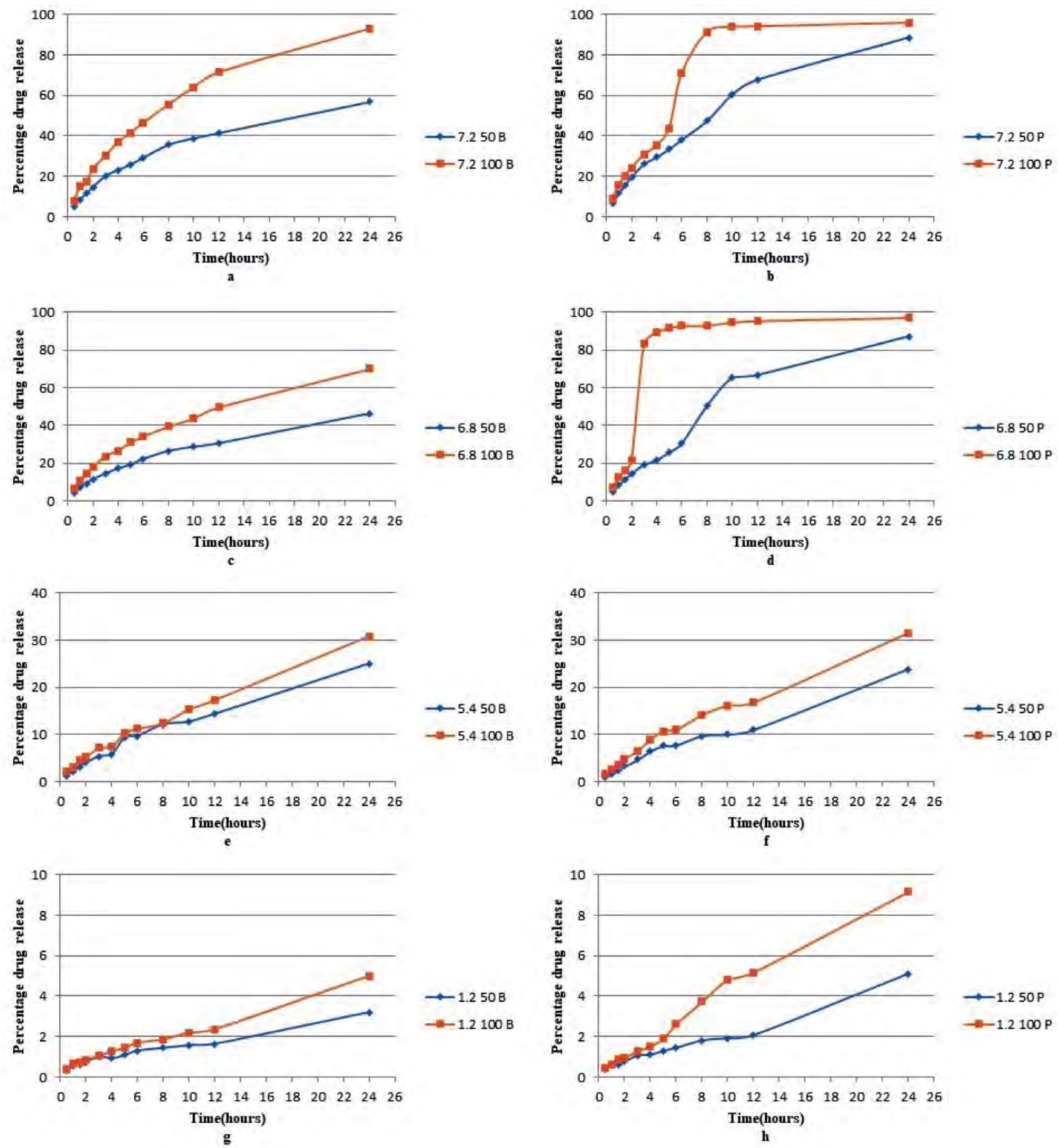

FIGURE 4. Influence of stirring speed on in vitro release of ibuprofen

( $p H 7.2 a$-rotative basket and b-rotative paddle; $p H 6.8 c$-rotative basket and d-rotative paddle; $p H 5.4 e-$ rotative basket and $f$-rotative paddle; $\mathrm{pH} 1.2 \mathrm{~g}$-rotative basket and $\mathrm{h}$ - rotative paddle)

Stirring speed can influence the release of ibuprofen from matrix tablets. At $100 \mathrm{rpm}$, because of much higher hydrodynamic forces, more active substance is released in comparison with $50 \mathrm{rpm}$. Also, a faster in vitro released was proved at $100 \mathrm{rpm}$. Release profiles generated in hydrochloric and acetic buffers are comparable $\left(50<\mathrm{f}_{2}<100\right)$ but the sameness is not achieved in phosphate buffers $\left(f_{2}<50\right)$.
Apparatus type is another factor that can influence the release of ibuprofen. In vitro release using paddle apparatus is faster in comparison with rotative basket apparatus. Sometimes excipients 
may get stuck on the sieve of the basket altering the release. Again, release profiles generated in hydrochloric and acetic buffers are comparable $\left(50<\mathrm{f}_{2}<100\right)$ but the sameness is not achieved in phosphate buffers $\left(f_{2}<50\right)$.

The modeling of release kinetics was performed by means of Weitbull, Korsmeyer-Peppas and Higuchi equations. Higuchi model resulted in a fair goodness of fit (sometimes poor especially at 100 rpm). On the other hand, good fitting was achived by using
Weitbull and Korsmeyer-Peppas (except kinetic model 6.8 100 P). All kinetic model seemed to have a better goodness of fit in phosphate buffers and $50 \mathrm{rpm}$ (both apparatuses) in comparison with hydrochloric and acetate (with the exceptions presented in Table 5).

In vitro release of ibuprofen from sustained release matrix tablets depends on dissolution media $\mathrm{pH}$ and release rate depends on judicious choice of dissolution test factors to made precise in vitro/in vivo correlations.

Conflict of interest: none declared Financial support: none declared

\section{REFERENCES}

1. Allen LV, Popovich NG, Ansel HC. Ansel's pharmaceutical dosage forms and drug delivery systems. Philadelphia: Lippincott Williams \& Wilkins, 2005.

2. Kataoka M, Yano K, Hamatsu Y et al. Assessment of absorption potential of poorly watersoluble drugs by using the dissolution/permeation system. Eur J Pharm Biopharm. 2013;85(3 Pt B):1317-1324.

3. Garbacz G, Klein S. Dissolution testing of oral modified-release dosage forms. J Pharm Pharmacol. 2012;64(7):944-968.

4. Patel N, Madan P, Lin S. Development and evaluation of controlled release ibuprofen matrix tablets by direct compression technique. Pharm Dev Technol. 2011;16(1):1-11.

5. Irvine J, Afrose A, Islam N. Formulation and delivery strategies of ibuprofen: Challenges and opportunities. Drug Dev Ind Pharm. 2018;44(2):173-183.

6. Jambhekar SS, Breen PJ. Drug dissolution: Significance of physicochemical properties and physiological conditions. Drug Discov Today. 2013;18(23-24):1173-1184.

7. Bühler V, Kollidon ${ }^{\circledR}$ SR. In: Kollidon ${ }^{\circledR}$ Polivinylpyrrolidone excipients for the pharmaceutical industry, BASF SE Pharma Ingredients \& Services, Ludwigshafen, Germany, 2008: 255-270.

8. Bojnanska E, Kalina M, Parizek L et al. Determination of critical parameters of drug substance influencing dissolution: A case study. Biomed Res Int. 2014;2014:929248.

9. Skripnik KKS, Riekes MK, Pezzini BR et al. Investigation of the Dissolution Profile of Gliclazide Modified-Release Tablets Using Different Apparatuses and Dissolution Conditions. AAPS PharmSciTech. 2017;18(5):1785-1794.

10. Zhang Y, Huo M, Zhou J et al. DDSolver: An add-in program for modeling and comparison of drug dissolution profiles. AAPS J. 2010;12(3):263-271.

11.Zuo J, Gao Y, Bou-Chacra N, Löbenberg R. Evaluation of the DDSolver software applications. Biomed Res Int. 2014;2014:204925.

12. Noce L, Gwaza L, Mangas-Sanjuan V, Garcia-Arieta A. Comparison of free software platforms for the calculation of the $90 \%$ confidence interval of $\mathrm{f}_{2}$ similarity factor by bootstrap analysis. Eur J Pharm Sci. 2020;146:105259. 